\title{
Numerical analysis of cement calciner fuel efficiency and pollutant emissions
}

\author{
Hrvoje Mikulčić • Eberhard von Berg • \\ Milan Vujanović $\cdot$ Peter Priesching • \\ Reinhard Tatschl $\cdot$ Neven Duić
}

Received: 30 November 2012/ Accepted: 23 February 2013/Published online: 27 March 2013

(c) Springer-Verlag Berlin Heidelberg 2013

\begin{abstract}
Efficient mixing of pulverized fuel and limestone particles inside cement calciners is important due to the reason that the calcination process directly affects the final fuel consumption. The focus of this paper is on the numerical analysis of cement calciner's operating conditions and pollutant emissions. The paper analyzes the influence of different amounts of fuel, mass flow of the tertiary air and the adiabatic wall condition on the decomposition rate of limestone particles, burnout rate of coal particles, and pollutant emissions of a newly designed cement calciner. Numerical models of calcination process and pulverized coal combustion were developed and implemented into a commercial computational fluid dynamics code, which was then used for the analysis. This code was used to simulate turbulent flow field, interaction of particles with the gas phase, temperature field, and concentrations of the reactants and products, by solving the set of conservation equations for mass, momentum, and enthalpy that govern these processes. A threedimensional geometry of a real industrial cement calciner
\end{abstract}

H. Mikulčić $(\bowtie) \cdot$ M. Vujanović · N. Duić

Faculty of Mechanical Engineering and Naval Architecture,

University of Zagreb, Ivana Lučića 5, 10000 Zagreb, Croatia

e-mail: hrvoje.mikulcic@fsb.hr

M. Vujanović

e-mail: milan.vujanovic@fsb.hr

N. Duić

e-mail: neven.duic@fsb.hr

E. von Berg · P. Priesching · R. Tatschl

AVL - AST, Hans List Platz 1, Graz, Austria

e-mail: eberhard.von.berg@avl.com

P. Priesching

e-mail: peter.priesching@avl.com

R. Tatschl

e-mail: reinhard.tatschl@avl.com was used for numerical simulations. The results gained by these numerical simulations can be used for the optimization of cement calciner's operating conditions, and for the reducing of its pollutant emissions.

Keywords Numerical modeling · Cement calciner · Fuel efficiency $\cdot$ Pollutant emissions $\cdot$ Calcination process

\section{Introduction}

Large amounts of different anthropogenic greenhouse gases, especially $\mathrm{CO}_{2}$, are emitted during the cement production process. Since it is well known that $\mathrm{CO}_{2}$ is the most important greenhouse gas, and that cement industry alone contributes to $5 \%$ of global anthropogenic $\mathrm{CO}_{2}$ emissions, continuous improvement of energy efficiency in the cement production process is needed (Mikulčić et al. 2013). In order to make the cement industry more greener and lower the $\mathrm{CO}_{2}$ emissions, increase of the energy efficiency comes first, followed by significant increase of the use of renewable energy sources for electricity generation, transportation, and other sectors, including process industry (Vad Mathiesen et al. 2011). Therefore, policy makers should uphold the good environmental practice in process industry, in order that the applied new technology avoids the use of additional energy, chemicals, and rare catalysts (Maroušek 2012). Aside from the studies investigating the $\mathrm{CO}_{2}$ emissions coming from the cement manufacturing process, several studies investigated the economical and ecological benefits of waste-to-energy technologies, e.g., using alternative fuels in cement plants. Villar et al. (2012) studied the waste-to-energy technologies in cement industry, and other continuous process industries, showing how GHG emissions and energy use can be reduced. Fodor and 
Klemeš (2011) investigated the potential use of pre-treated municipal solid waste as an alternative fuel for heat, power, and cement production. Fodor and Klemeš (2012), additionally to the investigation of benefits of using alternative fuels for cement production, studied the applicability and limitations of current and still developing waste-to-energy technologies. The study showed the influence of different waste-to-energy technologies on the environment. Mislej et al. (2012) investigated the combustion behavior and the environmental effect of using alternative fuels for heat generation in cement kilns. The study showed that by using alternative fuels, no notable negative environmental effects can be observed. These studies showed that there is a great potential, especially environmental, of using alternative fuels in cement production.

In recent years, due to stringent environmental measures, a more energy efficient cement production technology, the dry rotary kiln with preheater and calciner technology, is widely replacing the less energy efficiency kiln processes, e.g., wet rotary kiln process, and especially the shaft kiln process (Zhang et al. 2011). Cement calciners are pyroprocessing units found prior to the rotary kiln. Inside of them two strong thermo-chemical reactions occur. The first one is the combustion of pulverized solid fuels, and the second one is a strong endothermic reaction known as the calcination process (Mikulčić et al. 2012a). Controlling of the mixing of these two reactions, inside the cement calciner, is of particular importance since it directly affects the fuel consumption. With the aim of better understanding of the mixing phenomena, heat exchange processes and fluid flow different types of calciners have been investigated. Giddings et al. (2000) numerically investigated the performance of a fully operating cement calciner. The work showed the usefulness of the CFD and some important fluid flow characteristics of the simulated calciner, which cannot be experimentally measured. Huanpeng et al. (2004) performed a numerical study for the effect of different parameters on the dynamics of the twophase flow in a cement calciner. The study represented the transport properties of the solid phase with the kinetic theory of granular flow. Huang et al. (2005) numerically analyzed the formation of $\mathrm{NO}, \mathrm{CO}$, and $\mathrm{CO}_{2}$ in a cement calciner. The study showed that numerical predictions for burnout of coal particles, limestone decomposition, are in good agreement with the measured results. Hu et al. (2006) simulated a three-dimensional model of a dual combustor and calciner, by using the Eulerian frame for the gaseous phase and a Lagrangian frame for the solid phase. Huang et al. (2006) performed a three-dimensional simulation of a new type swirl-spray calciner. A new method for particlewall boundary condition and a new four-mixture-fraction model were developed to describe the transport phenomena in a calciner. The work showed that predicted results for limestone decomposition, coal burnout and the temperature at the exit of the calciner agreed well with measured results. Fidaros et al. (2007) presented a mathematical model and a parametric study of fluid flow and transport phenomena in a cement calciner. The work showed good prediction capabilities for temperature, velocity, and distribution of particles at the calciner exit, where measurements exist. All these studies show that there is still a need for further research and development of cement calciners. However, here should be noted that most of these CFD studies evaluated their numerical predictions with measurement data obtained on the calciner's exit. Due to the lack of measurement data for flow characteristics, and physical and chemical processes inside cement calciners, this approach is satisfactory when looking at pollutant emissions, decomposition ratio for limestone and burnout ratio for char particles. When it comes to, the details about burner region, wall region, or other regions with interesting flow phenomena, the mixing phenomena and the optimization of key physical and chemical processes inside cement calciners, our approach, with separately validated models for calcination process and pulverized coal combustion, improves the available CFD simulation methodology. Due to the high reliability of separately validated models, appropriate accuracy needed for the investigation of named details and optimization of key physical and chemical processes within cement calciners can be achieved with our approach. Since good mixing of both pulverized fuel and limestone particles is essential for a more energy efficient, and thus a cleaner cement production, engineers need to have an in-depth understanding of all relevant reactions that occur inside cement calciners. The use of experimental methods to investigate these reactions is complex and expensive, and thus the use of numerical simulations is a more attractive way to obtain the necessary information. Moreover, results gained by the numerical simulations give more information about the flow and transport processes inside a cement calciner, which is very difficult to obtain experimentally.

The purpose of this paper is to present a numerical analysis of cement calciner's operating conditions and pollutant emissions. The paper analyzes the influence of different amounts of fuel, mass flow of the tertiary air, and the adiabatic wall condition on the decomposition rate of limestone particles, burnout rate of coal particles, and pollutant emissions of a newly designed cement calciner. A three-dimensional geometry of a cement calciner was simulated with a commercial finite volume-based CFD code FIRE. This code was used to simulate turbulent flow field, temperature field, concentrations of the reactants and products, as well as the interaction of particles with the gas phase. Numerical models for the calcination process and pulverized coal combustion, e.g., the process providing the 
reaction enthalpy for limestone decomposition, were developed and implemented into the commercial computational fluid dynamics code, which was then used for the analysis. Based on these numerical simulations, interactions between the calcination process and pulverized coal combustion were studied, e.g., regarding cooling effects in the near wall regions, distribution of pollutants was analyzed, and particle trajectories of limestone and fuel were discussed. The results gained by these numerical simulations can be used for the optimization of cement calciner's operating conditions, and for the reducing of its pollutant emissions. Hence, by using numerical techniques and by optimizing cement calciner's operating conditions, less fuel is used, and therefore a more sustainable cement production is achieved.

\section{Numerical model}

In order to investigate the influence of different parameters on the decomposition rate of limestone particles, burnout rate of coal particles, and pollutant emissions from a cement calciner, all relevant thermo-chemical reactions must be treated, e.g., the calcination process and the combustion of pulverized coal. In this study, and in the most engineering applications today, the EulerianLagrangian method for solving the multiphase flow phenomena is used. In this approach, the solid particles are represented by finite numbers of particle groups, called parcels. It is assumed that all the particles within one parcel are similar in size and that they have the same physical properties. The motion and transport of the parcels, through the cement calciner, are tracked through the flow field using a Lagrangian formulation, while the gas phase is described by solving conservation equations using a Eulerian formulation. The trajectory of each parcel within the flow field is calculated using the Lagrangian scheme, which means that representative parcels are tracked by using a set of equations that describe their dynamic behavior as they move through the calculated flow field. The coupling between the solid and the gaseous phases is taken into account by introducing appropriate source terms for interfacial mass, momentum, and energy exchange. Lagrangian phase is solved in between two Eulerian phase time steps, with explicite integration method, providing the source terms for the Eulerian phase. Vice versa the solution of the Eulerian phase provides the ambient conditions for the Lagrangian phase.

The developed mathematical models used for the calculation of the calcination process and pulverized coal combustion are treated in the Lagrangian spray module, where thermo-chemical reactions occur inside a particle as well as between the particle and the gas phase. The developed models together with thermo-physical properties of the limestone, the lime and the components of the pit coal particles, as well as a particle radiation model, were integrated into the commercial CFD code via user-functions written in the FORTRAN programming language, in order to simulate the calcination and combustion process properly (Baburić et al. 2004).

\section{Multiphase flow equations}

The equations of continuum mechanics are based on the conservation laws for mass, momentum, and energy. The general form of the time averaged conservation equation for any dependent variable $\varphi$, of the continuous phase in the differential form is

$\frac{\partial}{\partial t}(\rho \varphi)+\frac{\partial}{\partial x_{j}}\left(\rho \varphi u_{j}\right)=\frac{\partial}{\partial x_{j}}\left(\Gamma_{\varphi} \frac{\partial \varphi}{\partial x_{j}}\right)+S_{\varphi}$,

where $\rho$ is the density, $u_{j}$ is the Cartesian velocity, $\Gamma_{\varphi}$ is the diffusion coefficient, and $S_{\varphi}$ is the source term of the dependent variable $\varphi$. The source term $S_{\varphi}$ is used for the coupling of the Eulerian and the Lagrangian phase.

The momentum differential equation of a parcel is as follows:

$m_{\mathrm{p}} \frac{\mathrm{d} u_{i \mathrm{p}}}{\mathrm{dt}}=F_{i \mathrm{dr}}+F_{i \mathrm{~g}}+F_{i \mathrm{p}}+F_{i \mathrm{~b}}$,

where $m_{\mathrm{p}}$ is the particle mass, $u_{i \mathrm{p}}$ is the particle velocity vector, $F_{i \mathrm{~g}}$ is a force including the effects of gravity and buoyancy, $F_{i \mathrm{p}}$ is the pressure force, $F_{i \mathrm{~b}}$ summarizes other external forces, and $F_{i \mathrm{dr}}$ is the drag force, given by

$F_{i \mathrm{dr}}=D_{\mathrm{p}} \cdot u_{\text {irel }}$.

Here $u_{\text {irel }}$ represents the particle relative velocity vector, and $D_{\mathrm{p}}$ is the drag function, defined as

$D_{\mathrm{p}}=\frac{1}{2} \rho_{\mathrm{g}} A_{\mathrm{p}} C_{\mathrm{D}}\left|u_{\text {irel }}\right|$,

where $\rho_{\mathrm{g}}$ is the gas density, $A_{\mathrm{p}}$ is the cross-sectional area of the particle, and $C_{\mathrm{D}}$ is the drag coefficient which is generally a function of the particle Reynolds number $\mathrm{Re}_{\mathrm{p}}$.

From the various formulations in literature for the drag coefficient of a single sphere, FIRE uses the following formulation from Schiller and Naumann (FIRE Manual 2011):

$C_{\mathrm{D}}= \begin{cases}\frac{24}{\operatorname{Re}_{\mathrm{p}}}\left(1+0.15 \operatorname{Re}_{\mathrm{p}}^{0.687}\right) & \operatorname{Re}_{\mathrm{p}}<10^{3} \\ 0.44 & \operatorname{Re}_{\mathrm{p}} \geq 10^{3}\end{cases}$

Calcination process

The numerical model of the calcination process presented by the following equation: 


$$
\mathrm{CaCO}_{3}(\mathrm{~s}) \stackrel{+178 \mathrm{~kJ} / \mathrm{mol}}{\longrightarrow} \mathrm{CaO}(\mathrm{s})+\mathrm{CO}_{2}(\mathrm{~g})
$$

used in this study takes into account the effects of decomposition pressure, temperature, diffusion, and pore efficiency. The developed numerical model is detailed enough to contain the relevant physical and chemical processes, yet simple enough for detailed CFD simulations. The model of the calcination process was thoroughly tested and validated by simulating experiments performed in the International Flame Research Foundation pipe reactor, for which measurements of limestone decomposition exist, in our previous studies (Mikulčić et al. 2012b). The comparison of numerical predictions with the experimental conversion rates showed that the developed model predicted very well the influence of all of the relevant process parameters (temperature, $\mathrm{CO}_{2}$ content, mass flow, etc.).

\section{Pulverized coal combustion}

The combustion of pulverized coal can be considered as a three-step process: devolatilisation process, combustion of char, and combustion of volatiles. The coal particle, composed of pit coal, sulfur, and ash, in first step at high temperatures undergoes the devolatilisation process. The devolatilisation process is the most important physicochemical change in the coal particle. During this step a significant loss of weight occurs, because of the release of volatile matter, the quantity and composition of which depend on the coal ingredients (see Eq. 7). A complex composition, represented via chemical formula $\mathrm{C}_{50} \mathrm{H}_{18} \mathrm{O}_{6} \mathrm{~N}_{2}$, for the pit coal is assumed, which has been chosen to meet the elemental composition of a typical coal as given in the literature (Schnell 1991).

$$
\begin{aligned}
\mathrm{C}_{50} \mathrm{H}_{18} \mathrm{O}_{6} \mathrm{~N}_{2} \rightarrow & 5 \mathrm{CO}+\mathrm{H}_{2} \mathrm{O}+\mathrm{CH}_{4}+\mathrm{H}_{2}+\mathrm{HCN}+\mathrm{NH}_{3} \\
& +37 \mathrm{C}+\mathrm{C}_{6} \mathrm{H}_{6} .
\end{aligned}
$$

For devolatilisation process (see Eq. 7), a single rate expression is used meaning that the devolatilisation rate $\mathrm{d} c_{\mathrm{pc}} / \mathrm{dt}$ is in a first-order dependency on the amount of pit coal remaining in the particle (Eq. 8)

$\frac{\mathrm{d} c_{\mathrm{pc}}}{\mathrm{dt}}=-k_{1} y_{\mathrm{pc}}$.

Here $y_{\mathrm{pc}}$ is the mass fraction of pit coal remaining in the particle and $k_{1}$ is the kinetic rate defined by an Arrhenius type expression including a pre-exponential factor $k_{0,1}$ and an activation energy $E_{1}$ (Eq. 9).

$k_{1}=k_{0,1} \exp \left(-E_{1} / R T_{\mathrm{p}}\right)$

The values of the kinetic constants $\left(k_{0,1}\right.$ is the pre-exponential factor and $E_{1}$ is the activation energy) for different pit coal devolatilisation processes are obtained from the literature (Görner 1991).

Parallel to the devolitilisation, sulfur is oxidized to form $\mathrm{SO}_{2}$ (Eq. 10), and the char is oxidized to form $\mathrm{CO}$ and $\mathrm{CO}_{2}$ taking into account a mechanism factor depending on coal particle size and temperature (Eq. 11).

$$
\begin{aligned}
\mathrm{S} & +\mathrm{O}_{2} \rightarrow \mathrm{SO}_{2} \\
\mathrm{C} & +\frac{1}{f_{\mathrm{m}}} \mathrm{O}_{2} \stackrel{-395 \mathrm{~kJ} / \mathrm{mol},-110 \mathrm{~kJ} / \mathrm{mol}}{\longrightarrow}\left(2-\frac{2}{f_{\mathrm{m}}}\right) \mathrm{CO} \\
& +\left(\frac{2}{f_{\mathrm{m}}}-1\right) \mathrm{CO}_{2} .
\end{aligned}
$$

In Eq. 11, $f_{\mathrm{m}}$ represents the mechanism factor (Görner 1991), which ranges between 1 and 2, causing predominant generation of $\mathrm{CO}$ for temperatures higher of approximately $900 \mathrm{~K}$, and predominant production of $\mathrm{CO}_{2}$ for temperatures lower than $900 \mathrm{~K}$.

Char combustion (Eq. 11) is modeled according to the kinetics/diffusion limited reaction model of Baum and Street (1971). The model assumes that the reaction rate of char combustion is limited either by the kinetics of the heterogeneous reaction $k_{2}^{\text {ch }}$ or by the oxygen's diffusion into the particle's mass expressed by the value of $k_{2}^{\mathrm{ph}}$ as presented in Eqs. 12-15.

$\frac{\mathrm{d} c_{\mathrm{c}}}{\mathrm{dt}}=-k_{2} A_{\mathrm{p}} \mathrm{p}_{\mathrm{ox}} y_{\mathrm{c}}$

$k_{2}=\frac{k_{2}^{\mathrm{ch}} \cdot k_{2}^{\mathrm{ph}}}{k_{2}^{\mathrm{ch}}+k_{2}^{\mathrm{ph}}}$

$k_{2}^{\mathrm{ch}}=k_{0,2}^{\mathrm{ch}} \cdot \exp \left(-E_{2}^{\mathrm{ch}} / R T\right)$

$k_{2}^{\mathrm{ph}}=\frac{24 \cdot f_{\mathrm{m}} \cdot D_{0}}{R \cdot d_{\mathrm{p}} \cdot T_{0}^{1.75}} T^{0.75} \cdot 10^{5}$

In Eq. 8, the char reaction rate $\mathrm{d} c_{\mathrm{c}} / \mathrm{dt}$ in terms of rate of change of mass fraction is given. Here $y_{c}$ is the mass fraction of char remaining in the particle, $A_{\mathrm{p}}$ is the specific particle surface, $p_{\text {ox }}$ is the oxygen partial pressure, and $k_{2}$ is the overall kinetic rate of char combustion. In Eq. 14, the kinetics of the heterogeneous reaction $k_{2}^{\text {ch }}$ are defined as an Arrhenius type expression with a pre-exponential factor $k_{0,1}^{\mathrm{ch}}$ and activation energy $E_{2}^{\mathrm{ch}}$. In Eq. $15, D_{0}$ is the oxygen diffusion coefficient, $d_{\mathrm{p}}$ is the particle diameter, and $T_{0}$ is the reference temperature. The values of the kinetic constants for the char combustion model are obtained from the literature (Görner 1991).

Named heterogeneous reactions (Eqs. 7, 10, and 11) cause mass transfer sources and sinks to the gas phase and particles, which are described by rate equations for sulfur and pit coal consumption, char production from devolitilisation and consumption from oxidation. After the completion of the char combustion, the particle is considered as 
inert without any further chemical interaction with the gas phase.

The homogeneous reactions of volatiles released during the devolitilisation, are treated within the gas phase reactions module of the used CFD code. A detailed chemistry approach is used for each of the homogeneous reaction. The source terms accounting for the gas phase reactions in the species transport equations and in the gas phase energy equation are calculated with reaction rates depending on species concentrations and temperature, e.g., reaction rates are defined by an Arrhenius law. The modeled homogeneous reactions include tar (here $\mathrm{C}_{6} \mathrm{H}_{6}$ was chosen as tar representative), CO oxidation (Görner 1991), NOx formation, and the combustion of methane, which is treated via the four-step Jones-Lindstedt mechanism (Jones and Lindstedt 1988). Equation 16 represents the tar $\left(\mathrm{C}_{6} \mathrm{H}_{6}\right)$ oxidation, whereas Eqs. 17 and 18a-18d represent the CO oxidation and the four-step Jones-Lindstedt mechanism for methane combustion.

$$
\begin{aligned}
& \mathrm{C}_{6} \mathrm{H}_{6}+3 \mathrm{O}_{2} \rightarrow 6 \mathrm{CO}+3 \mathrm{H}_{2} \\
& \mathrm{CO}+\frac{1}{2} \mathrm{O}_{2} \rightarrow \mathrm{CO}_{2} \\
& \mathrm{CH}_{4}+\frac{1}{2} \mathrm{O}_{2} \rightarrow \mathrm{CO}+2 \mathrm{H}_{2} \\
& \mathrm{CH}_{4}+\mathrm{H}_{2} \mathrm{O} \rightarrow \mathrm{CO}+3 \mathrm{H}_{2} \\
& \mathrm{CO}+\mathrm{H}_{2} \mathrm{O} \leftrightarrow \mathrm{CO}_{2}+\mathrm{H}_{2} \\
& \mathrm{H}_{2}+\frac{1}{2} \mathrm{O}_{2} \rightarrow \mathrm{H}_{2} \mathrm{O}
\end{aligned}
$$

Generally, it is considered that the main NO formation mechanism in coal-fired systems is the fuel-NO formation mechanism. Fuel-NO is formed from the nitrogen bounded in the coal. During the devolatilisation nitrogen is released as $\mathrm{HCN}$ and $\mathrm{NH}_{3}$, which react with oxygen containing species in the flame and produce NO (Molina et al. 2009). Fuel-NO formation from HCN is treated by Eqs. 19a-19b (Görner 1991):

$$
\begin{aligned}
& 4 \mathrm{HCN}+5 \mathrm{O}_{2} \rightarrow 4 \mathrm{NO}+4 \mathrm{CO}+2 \mathrm{H}_{2} \mathrm{O}, \\
& 4 \mathrm{HCN}+6 \mathrm{NO} \rightarrow 5 \mathrm{~N}_{2}+4 \mathrm{CO}+2 \mathrm{H}_{2} \mathrm{O},
\end{aligned}
$$

and the De Soete mechanism (De Soete 1975) is used to describe the fuel-NO formation from the $\mathrm{NH}_{3}$ :

$$
\begin{aligned}
& \mathrm{NH}_{3}+\mathrm{O}_{2} \rightarrow \mathrm{NO}+\mathrm{H}_{2} \mathrm{O}+0.5 \mathrm{H}_{2}, \\
& \mathrm{NH}_{3}+\mathrm{NO} \rightarrow \mathrm{N}_{2}+\mathrm{H}_{2} \mathrm{O}+0.5 \mathrm{H}_{2} .
\end{aligned}
$$

\section{Computational details}

The modeled calciner (Fig. 1) consists of two vertical cylinder parts and a cylinder connecting them. On the top of the first vertical cylinder the swirl burner is positioned, and in the second vertical cylinder the hot gas stream from the rotary kiln is used to enhance the calcination process. At the bottom of the second vertical cylinder, a converging-diverging section is used to increase the velocity of the incoming hot stream from the rotary kiln. The entire model is $24 \mathrm{~m}$ high, with the diameter of the first cylindrical part, the burner chamber, of $5.5 \mathrm{~m}$, and with the diameter of the second cylindrical part of $4.5 \mathrm{~m}$. The connecting cylinder is positioned at $60^{\circ}$ angles and is $4 \mathrm{~m}$ in diameter. At the top of the first vertical cylinder, two limestone and two tertiary air inlets are positioned diametrically opposite each other. The top of the second vertical cylinder is the calciner's outlet.

The grid-size dependency was analyzed in our previous study (Mikulčić et al. 2012b), and based on these results, 47,000 cells were employed to discretize the computational domain (Fig. 1) used in the simulation of the cement calciner. The differencing scheme used for momentum, continuity, and enthalpy balances was MINMOD Relaxed

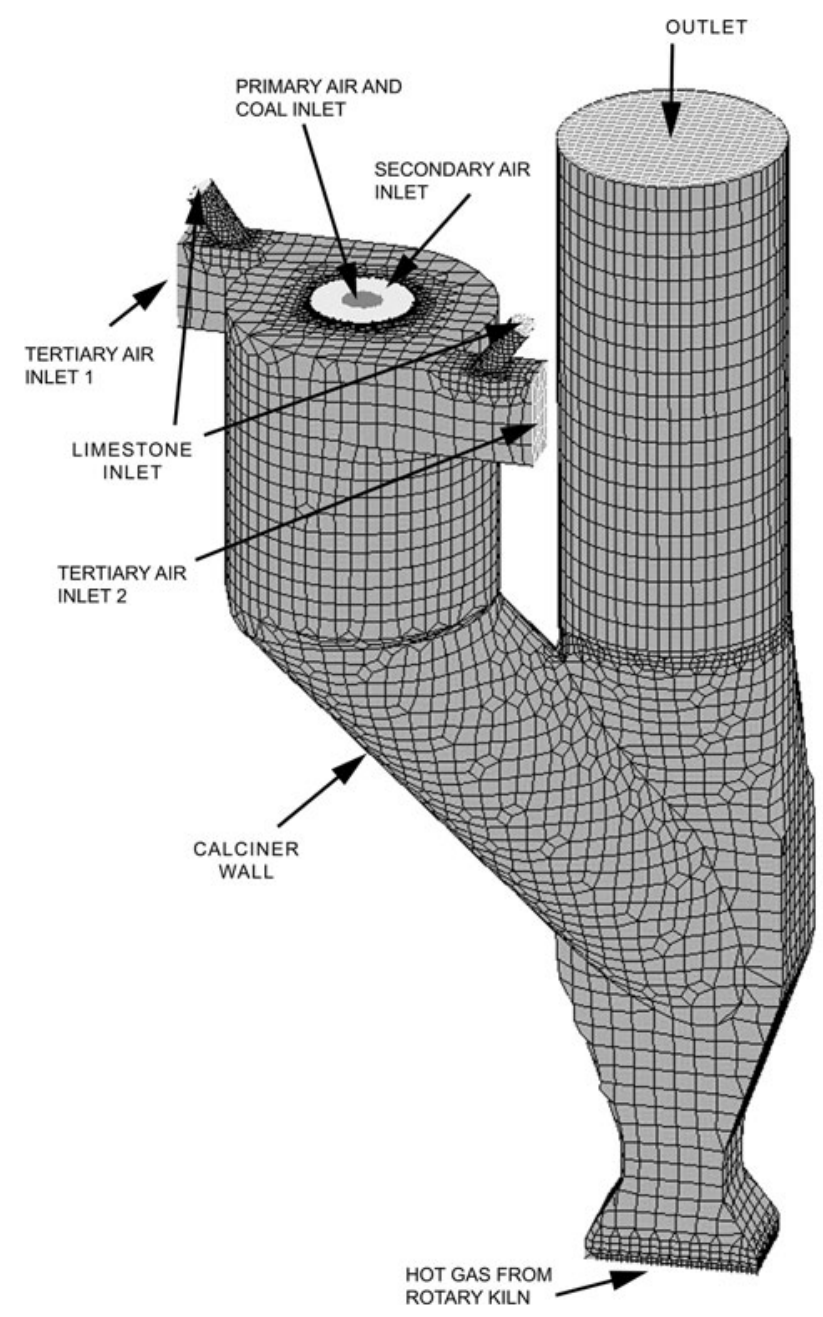

Fig. 1 Calciner geometry and boundary conditions 
(FIRE Manual 2011), and for the turbulence and scalar transport equations, an Upwind scheme was applied. Turbulence was modeled by the standard $k-\varepsilon$ model. This is the most widely used turbulence model in CFD simulations of practical engineering applications, and it is generally accepted that the $k-\varepsilon$ model yields realistic predictions of major mean-flow features in most situations. The P-1 radiation model (Sazhin et al. 1996) was used to model the radiative heat transfer and the effects of particle radiation from the limestone and coal particles. The boundary conditions used for the cement calciner's reference case simulation are given in Table 1, and the variation of operating conditions for five other simulation cases are summarized in Table 2. The values for the reference simulation case were the input data that were provided to the authors. In Table 2, the written percentage marks the difference between the calculated case and the reference simulation case, and the dash symbols' that there is no difference between boundary conditions of the calculated case and the reference simulation case.

\section{Results and discussion}

Figure 2 shows the streamlines of the flow inside the calculated calciner for the reference case. As can be seen, in the left vertical cylinder part, the burner chamber part, and in the connecting cylinder, the flow is highly swirled. The reason for this highly swirled flow is the big mass flow of the tertiary air that enters at the top of the left vertical cylinder. The highly swirled flow enhances the mixing of pulverized limestone and coal particles, and due to that reason majority of the limestone decomposition, e.g., calcination process, occurs in this part of the calciner. What can also be observed is a small region with recirculation that occurs in the right vertical cylinder part of the calciner. Afterwards the recirculation region vanishes due to the high velocity stream coming from the bottom of the right vertical cylinder part. This high velocity stream is caused by the big mass flow of hot gases entering the calciner from the rotary kiln. All particles are due to the high velocity stream of hot gases from the rotary kiln, blown to the upper calciner outlet. For a plant operator or a practical engineer, understanding of the flow characteristics inside a calciner is of essential importance, since limestone and coal need several seconds to completely decompose and burnout.

Figure 3 shows the velocity field inside the calculated calciner for the reference case. The cross section is positioned $20 \mathrm{~m}$ from the bottom of the calciner. On the left hand side of the Fig. 3 the velocity field in the left vertical cylinder, near burner region together with tertiary air inlet is shown. As can be seen, in the near burner region, the flow is highly swirled. The highest velocities are in the outer cylinder part, due to the big mass flow of the tertiary air, and lower velocities can be observed in the center part of the cylinder, where the burner is positioned. Limestone particles are carried by the high velocity flow, and pulverized coal particles are carried by the lower velocity flow. On the right hand side of the Fig. 3 the velocity field in the right vertical cylinder, close to the calcirer's outlet, is shown. As can be observed, in the right vertical cylinder the flow is concentrated on one side. The highest velocities

Table 1 Reference simulation case boundary conditions

\begin{tabular}{|c|c|c|c|c|c|c|c|}
\hline Notation & Mass flow rate $(\mathrm{kg} / \mathrm{h})$ & $T\left({ }^{\circ} \mathrm{C}\right)$ & $\rho\left(\mathrm{kg} / \mathrm{m}^{3}\right)$ & $d_{\mathrm{p}}(\mu \mathrm{m})$ & $\mathrm{O}_{2}(\operatorname{mass} \%)$ & $\mathrm{N}_{2}(\operatorname{mass} \%)$ & $\mathrm{CO}_{2}(\operatorname{mass} \%)$ \\
\hline Limestone $1+2$ & 147,900 & 720 & 3,100 & 12 & & & \\
\hline Tertiary air 1 & 49,600 & 950 & 1.292 & & 28 & 71.8 & 0.2 \\
\hline Tertiary air 2 & 49,600 & 950 & 1.292 & & 28 & 71.8 & 0.2 \\
\hline Primary air & 16,200 & 80 & 1.292 & & 28 & 71.8 & 0.2 \\
\hline Secondary air & 33,065 & 950 & 1.292 & & 28 & 71.8 & 0.2 \\
\hline Coal & 14,811 & 60 & 1,300 & 50 & & & \\
\hline Hot gas from rotary kiln & 110,600 & 1,100 & 1.292 & & 8 & 72 & 20 \\
\hline Outlet & Static pressure & $10^{5} \mathrm{~Pa}$ & & & & & \\
\hline
\end{tabular}

Table 2 Variation of operating conditions for different cases

\begin{tabular}{|c|c|c|c|c|c|}
\hline Calculation & Case $1(\%)$ & Case $2(\%)$ & Case $3(\%)$ & Case $4(\%)$ & Case 5 \\
\hline Tertiary air 1 & -20 & +20 & - & - & - \\
\hline Tertiary air 2 & -20 & +20 & - & - & - \\
\hline Coal & - & - & -10 & +10 & - \\
\hline Adiabatic wall condition & - & - & - & - & Used \\
\hline
\end{tabular}




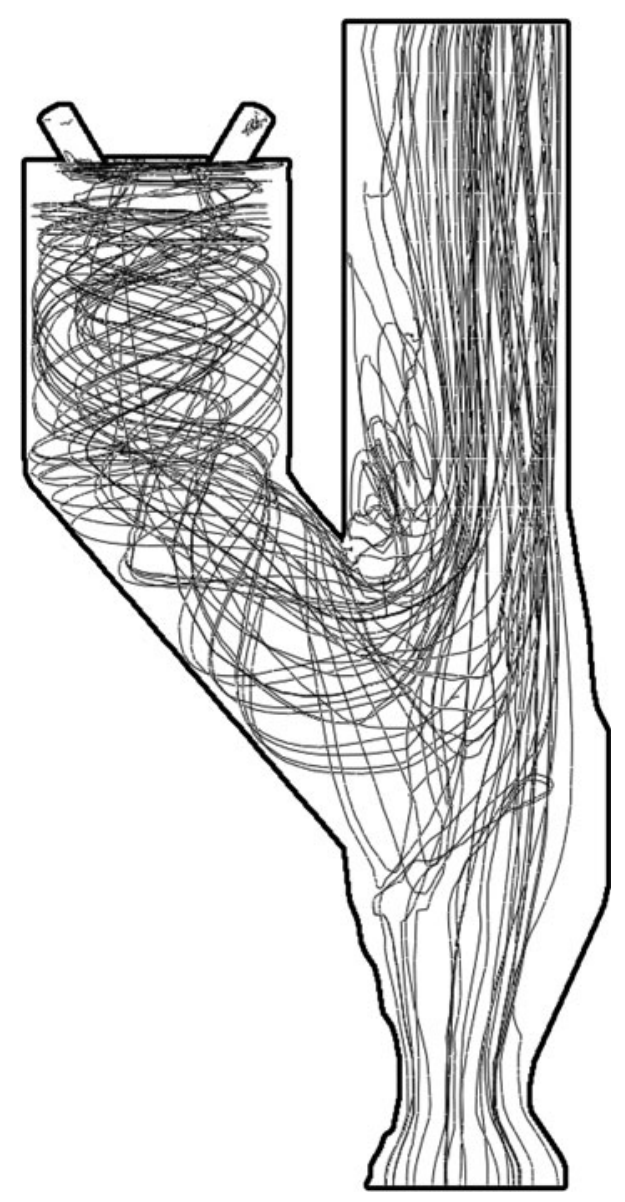

Fig. 2 Preview of flow characteristics inside the calculated calciner

are in the right cylinder part, due to the big mass flow of the hot gases coming from the rotary kiln and their mixing with the flow that is coming from calciner's left vertical cylinder. Lower velocities can be observed in the left part of the cylinder, where the recirculation region is positioned. Here, both decomposed limestone and burned coal particles are carried by the high velocity. These results give valuable information to plant operators, since high particle concentration on one side of the cylinder can cause wall wearing.

Figure 4 shows from left to right, the char, ash, limestone, and lime mass fraction in particles, and their distribution inside the calculated calciner for the reference case. The "empty" regions indicate the regions where conversion of char to $\mathrm{CO}, \mathrm{CO}_{2}$, and ash, and limestone to lime, to a large extent, has already been completed. In this figure, the decrease of char and limestone mass fraction and the corresponding increase of ash and lime mass fraction toward the inlet can be observed. Also, it can be seen that the char and ash particles are located in the middle of the burner chamber, while limestone and lime particles are located in the outer part of the burner chamber, close the calciner wall. Due to the location of limestone particles, and since the calcination process is a strong endothermic reaction, the thermal load on calciner walls is reduced.

Figure 5 shows the $\mathrm{CO}$ mass fraction, temperature field, and NO mass fraction inside the calculated calciner for the reference case. It can be seen that highest concentrations of $\mathrm{CO}$ and NO occur close to the burner. The previous statement that due to the location of limestone particles in the outer part of the burner chamber, the thermal load on calciner walls is reduced, is confirmed when looking at the shown temperature field. Here, it can be seen that calcination lowered the temperature in the near wall region, and in that way protects the calciner walls.

Figure 6 shows the temperature field inside the calciner for the six calculated cases. In this figure from left to right the temperature fields for the reference case, cases 1-5 are shown. The figure shows that in all cases in the near wall regains the temperature is lower due to the calcination process. However, it can be seen that cases 2 and 4 have slightly higher temperatures in the connecting cylinder, meaning that the wall thermal load in those two cases is higher. Such results are valuable for plant operators, since they give information that can have an impact on calciners endurance.

Figure 7 shows the $\mathrm{CO}_{2}$ mass fraction inside the calciner for the six calculated cases. In this figure from left to right the $\mathrm{CO}_{2}$ mass fraction for the reference case, cases 1-5 are shown. The figure shows that in all cases the highest concentration of $\mathrm{CO}_{2}$ is in the connecting cylinder, where most of the calcination process takes place. What can also be seen from this figure is that in cases 1,4 , and 5 a slightly higher concentration of $\mathrm{CO}_{2}$ in the connecting cylinder and in the right vertical cylinder can be observed. This is also valuable information for plant operators, since it is known that the calcination process can extinguish the combustion process.

Although understanding of flow characteristics and thermo-chemical reactions inside cement calciners are important, plant operators and practical engineers are, due to increased environmental awareness, more and more interested in what comes out from the cement calciner. For that reason, in this study, six calculation cases with different parameters were calculated, in order to see the influence of these parameters on fuel efficiency and pollutant emissions. Due to asymmetric distribution of particles and pollutants on the calciner outlet, in Table 3 and Figs. 8 and 9 average values for observed parameters are given.

In Table 3, summarized results for six different cases are shown. As can be seen, for different cases the calciner outlet temperature is almost the same, and this corresponds to the values of calciner outlet temperatures that have been reported in the literature (Zhang et al. 2011). What can also be observed is that almost all cases give the same NO concentration on the calciner outlet. 
Fig. 3 Velocity field inside two vertical cylinders of the calculated calciner
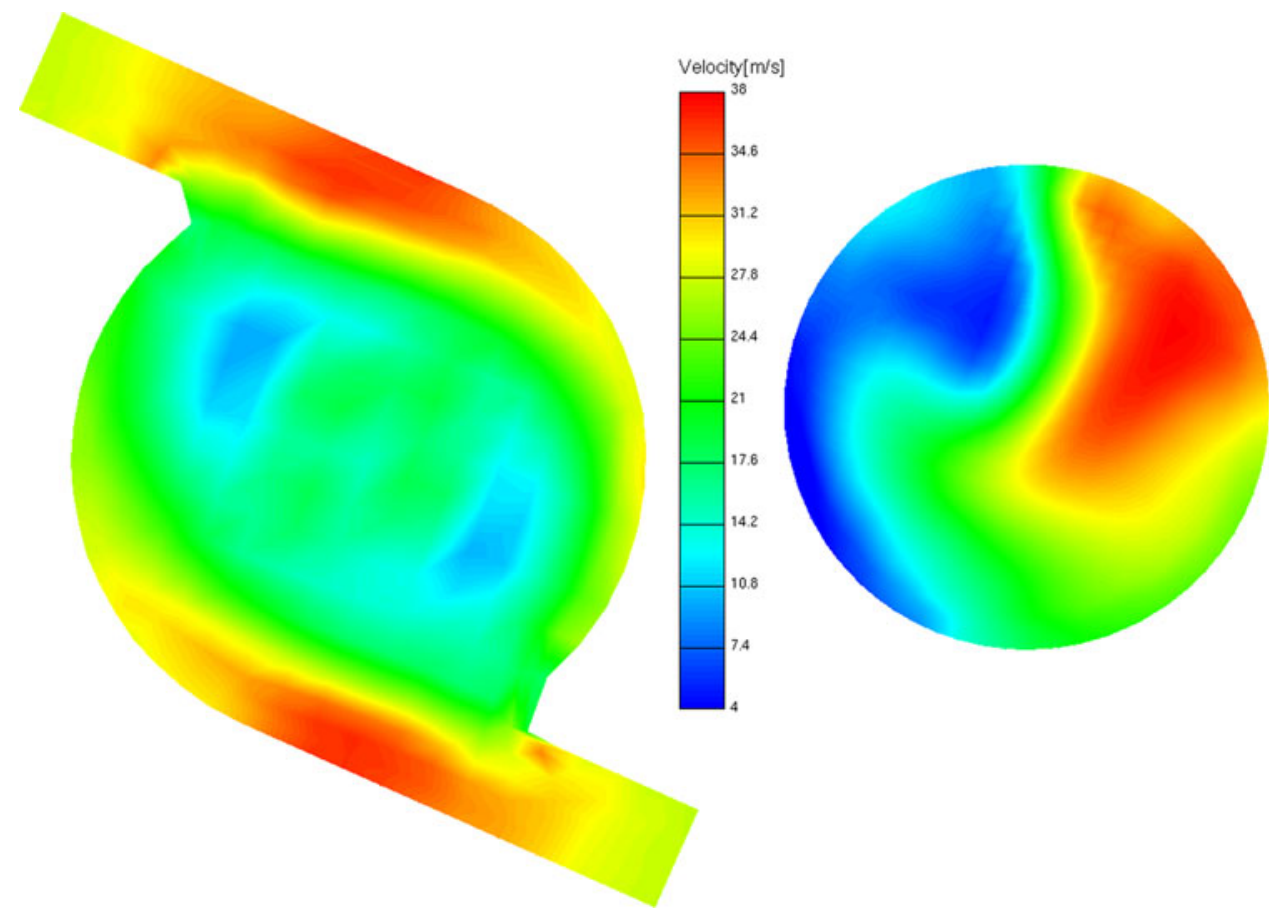
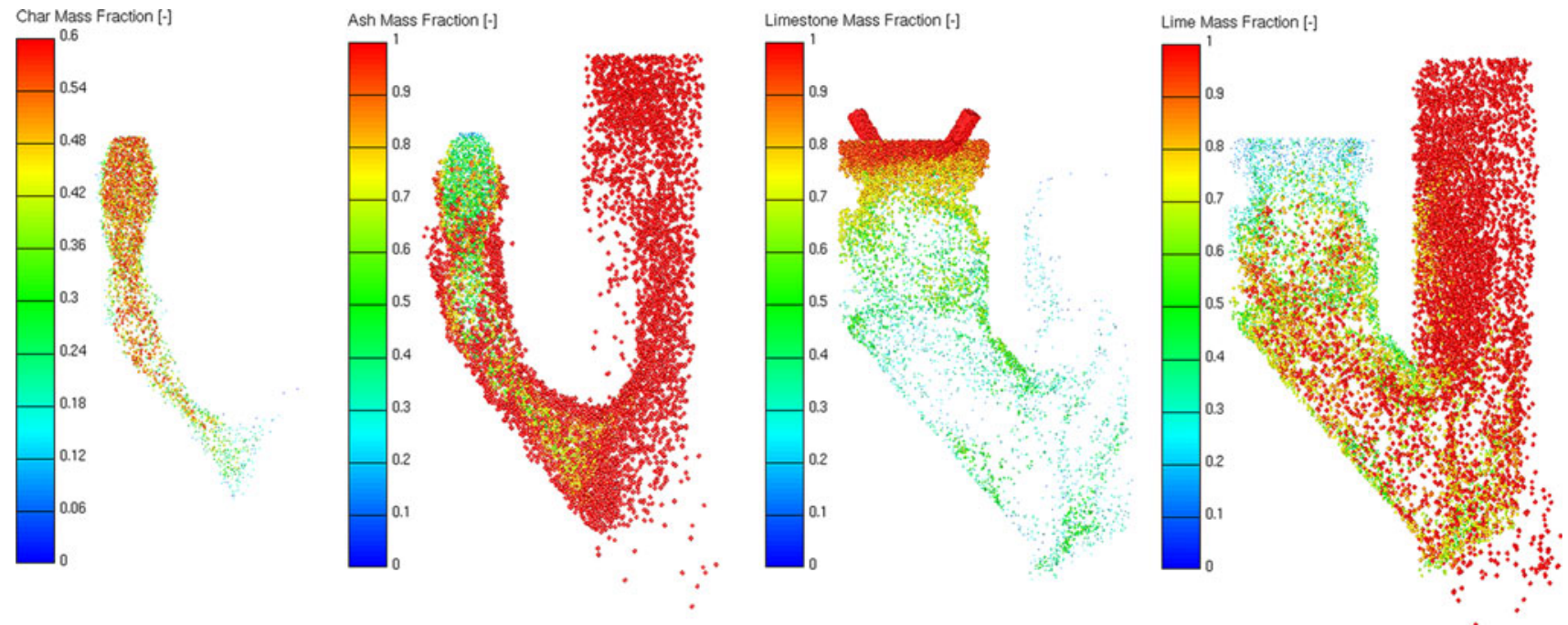

Fig. 4 Char, ash, limestone, and lime mass fraction in particles

Figure 8 shows the comparison of burnout and decomposition ratios on the calciner outlet. It can be seen that for the reference case and cases 1,4 , and 5 almost same values for burnout and decomposition ratio are obtained. However, in cases 2 and 3 lower decomposition ratios are obtained. For case 2, this can be explained due to shorter time limestone spends in the calciner. Limestone is carried by the tertiary air, and in this case higher mass flow of the tertiary air was used. For the case 3, the lower decomposition rate can be explained by the lack of the enthalpy needed for the calcination reaction. The enthalpy is provided by the combustion of fuel, and in this case $10 \%$ less fuel was used.

Figure 9 shows the comparison of $\mathrm{CO}$ concentrations in terms of mass fraction on the calciner outlet. It can be seen that the reference case has the lowest $\mathrm{CO}$ emissions. It seems that in terms of $\mathrm{CO}$ emissions the reference case shows to be the optimal set-up of calciner's operating conditions.

To ensure the adequate conditions for a complete calcination reaction inside cement calciners, good mixing of limestone and pulverized fuel particles are essential for a 


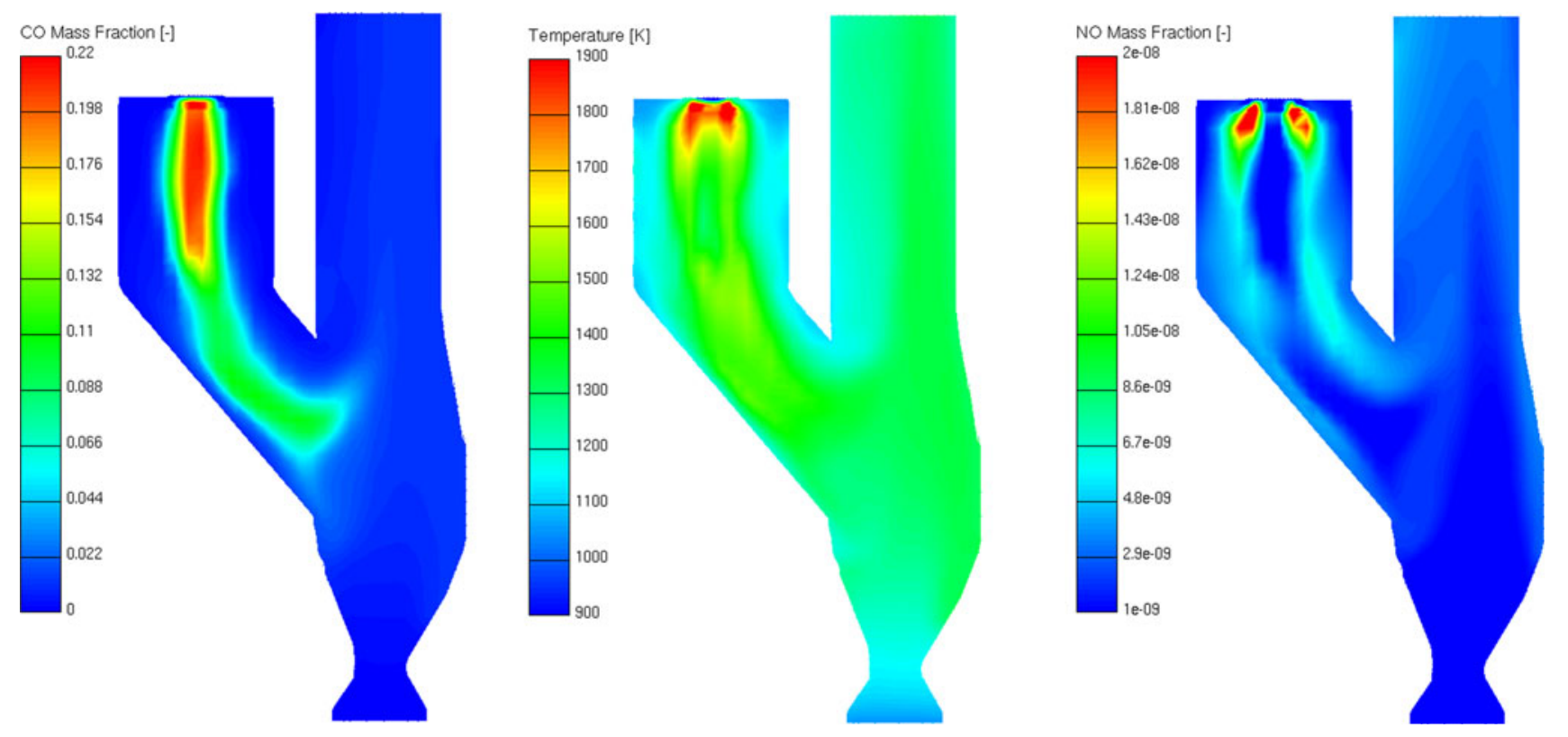

Fig. 5 CO mass fraction, Temperature field, and NO mass fraction inside the calculated calciner

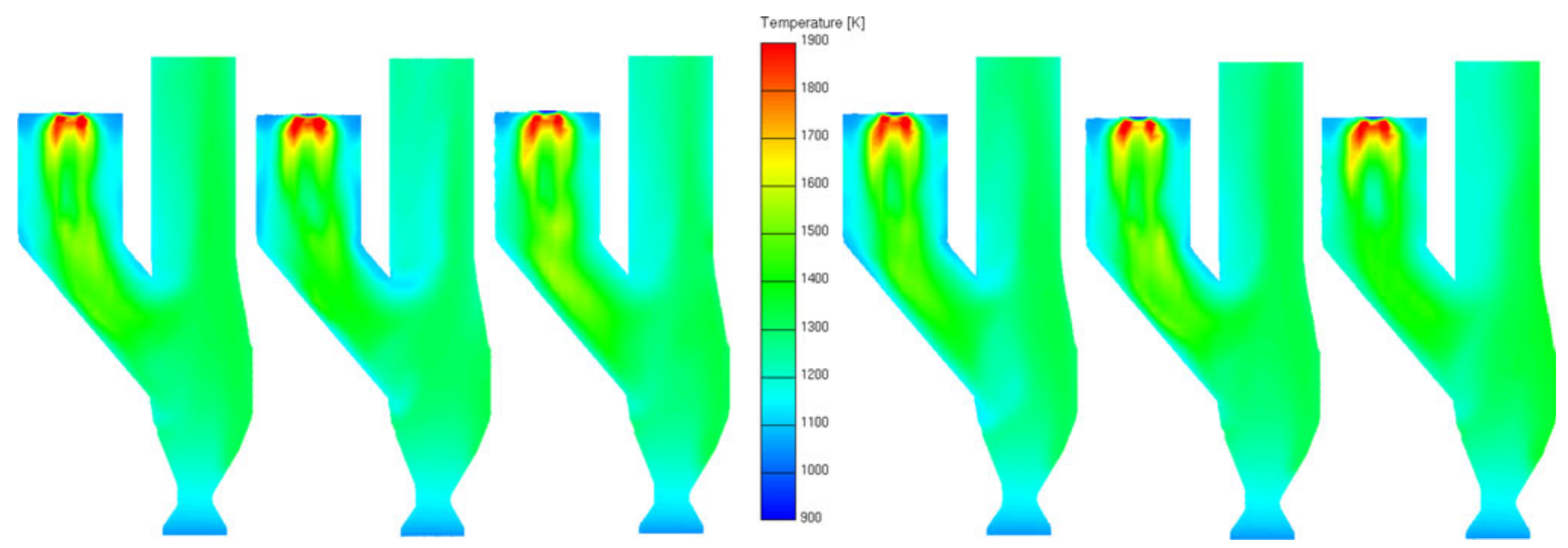

Fig. 6 Temperature fields inside the calciner for the six calculated cases

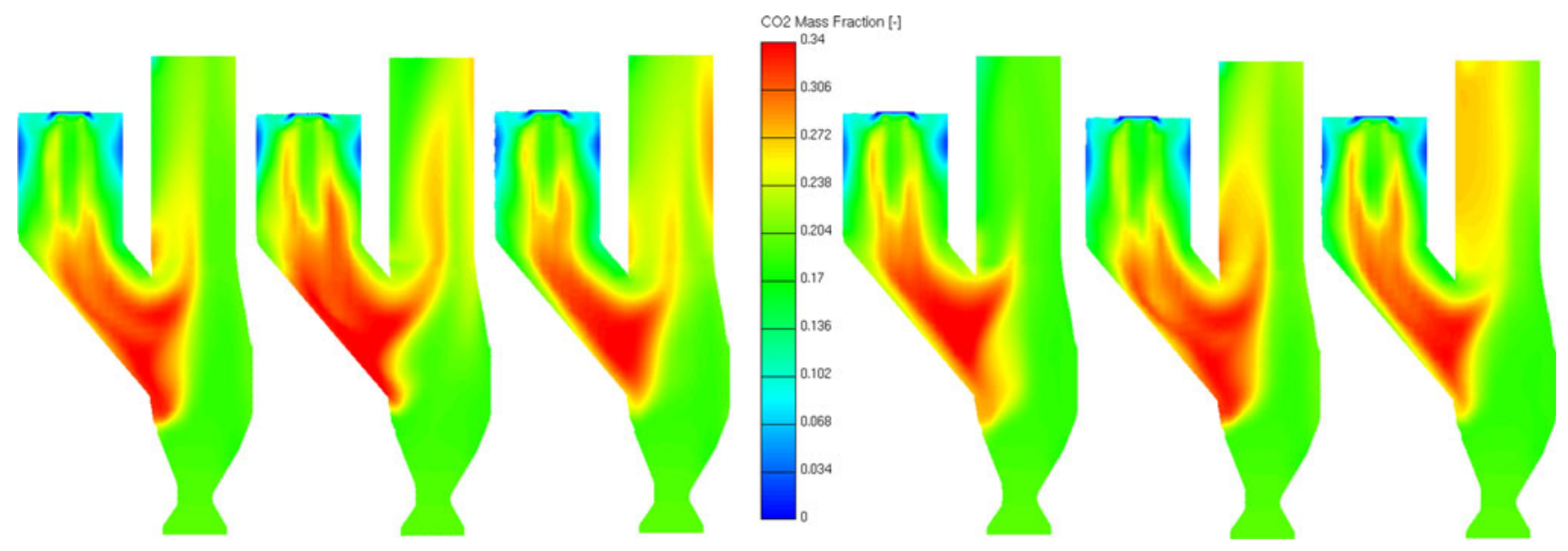

Fig. $7 \mathrm{CO}_{2}$ mass fraction inside the calciner for the six calculated cases 
Table 3 Summarized calciner outlet results

\begin{tabular}{|c|c|c|c|c|c|c|}
\hline & Reference case & $\begin{array}{l}\text { Case } 1 \\
(-20 \% \text { tert. air })\end{array}$ & $\begin{array}{l}\text { Case } 2 \\
(+20 \% \text { tert. air })\end{array}$ & $\begin{array}{l}\text { Case } 3 \\
(-10 \% \text { fuel })\end{array}$ & $\begin{array}{l}\text { Case } 4 \\
(+10 \% \text { fuel })\end{array}$ & $\begin{array}{l}\text { Case } 5 \\
\text { (adiabatic) }\end{array}$ \\
\hline $\begin{array}{l}\text { NO concentration } \\
(\mathrm{kg} / \mathrm{kg})\end{array}$ & $3.329 \mathrm{E}-09$ & $3.442 \mathrm{E}-09$ & $3.453 \mathrm{E}-09$ & $4.084 \mathrm{E}-09$ & $2.999 \mathrm{E}-09$ & $2.932 \mathrm{E}-09$ \\
\hline $\begin{array}{l}\text { CO concentration } \\
(\mathrm{kg} / \mathrm{kg})\end{array}$ & 0.0031115 & 0.0095239 & 0.0075068 & 0.0071763 & 0.0107001 & 0.0096996 \\
\hline $\begin{array}{l}\mathrm{CO}_{2} \text { concentrations } \\
(\mathrm{kg} / \mathrm{kg})\end{array}$ & 0.2549952 & 0.2112467 & 0.2212173 & 0.2013529 & 0.2283265 & 0.2492649 \\
\hline $\begin{array}{l}\mathrm{O}_{2} \text { concentration } \\
\quad(\mathrm{kg} / \mathrm{kg})\end{array}$ & 0.0893802 & 0.0912999 & 0.1110957 & 0.1112074 & 0.0960943 & 0.1006402 \\
\hline $\begin{array}{l}\mathrm{SO}_{2} \text { concentration } \\
\quad(\mathrm{kg} / \mathrm{kg})\end{array}$ & $2.667 \mathrm{E}-06$ & $1.648 \mathrm{E}-06$ & $1.362 \mathrm{E}-06$ & $1.152 \mathrm{E}-06$ & $1.788 \mathrm{E}-06$ & $1.676 \mathrm{E}-06$ \\
\hline Outlet mean temperature $(\mathrm{K})$ & $1,171.8805$ & $1,172.4826$ & $1,174.7325$ & $1,174.6059$ & $1,172.9354$ & $1,173.8705$ \\
\hline $\begin{array}{l}\text { Decomposition ratio } \\
(-)\end{array}$ & 0.9990101 & 0.9978904 & 0.9859680 & 0.9262303 & 0.9964629 & 0.9990001 \\
\hline Burnout ratio $(-)$ & 0.9990011 & 0.9990012 & 0.9990014 & 0.9990015 & 0.9990014 & 0.9990011 \\
\hline
\end{tabular}

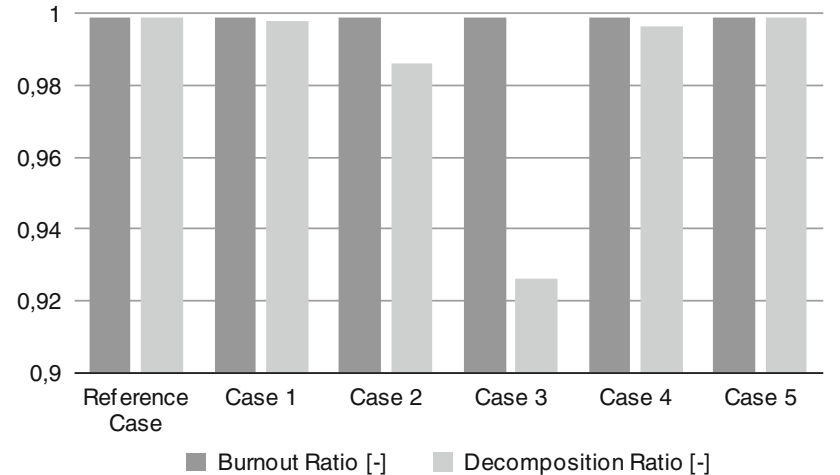

Fig. 8 Comparison of burnout and decomposition ratios

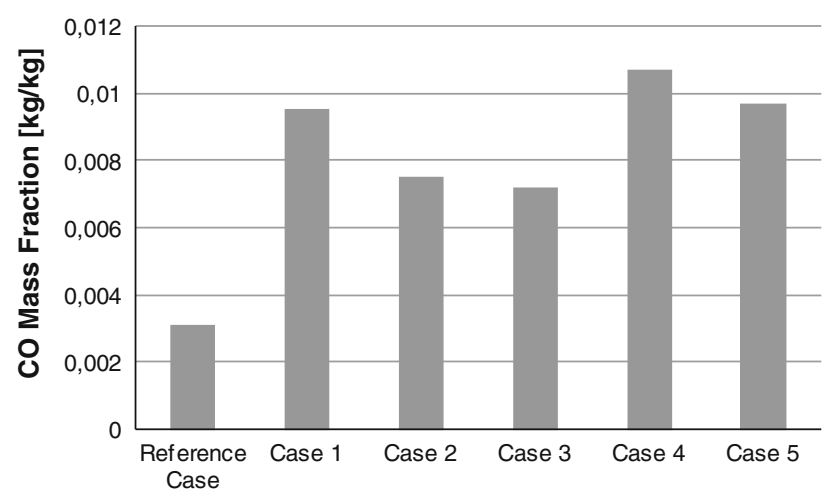

Fig. 9 Comparison of $\mathrm{CO}$ concentrations

more energy efficient cement production. The use of experimental methods to investigate the mixing phenomena is complex, expensive, and not that usual nowadays, thus the use of numerical techniques is a more attractive way to obtain the necessary information. Even more, results gained by the numerical investigations give detailed information about the flow characteristics and thermochemical reactions that occur inside a cement calciner.

The results gained by this study show some interesting features of the flow, and particle distribution which help to understand the operating conditions of the calculated cement calciner. The results show that the highly swirled flow in the left vertical cylinder and the connecting cylinder prolongs the particle residence time, and enhances the calcination process. The distribution of particles in the left vertical cylinder and the connecting cylinder shows that the wall is protected by the nature of the endothermic calcination process. By taking the heat, in the near wall region, provided by the combustion of pulverized coal, limestone particles decompose and lower the thermal load on the cement calciner wall. Furthermore, the gained results show that the developed models for the calcination process (Mikulčić et al. 2012b) and the pulverized coal combustion coupled with a commercial CFD code, form a promising tool for optimization of cement calciner's fuel consumption and pollutant emissions. That was the focus of this study. Although the comparison of numerically obtained results with experimental data is essential, experimental measurements were not available for this calciner. Nowadays, it is not usual to place measurement equipment in a fully operating industrial calciner. However, it will be very much desirable to have such experimental data in the future.

\section{Conclusion}

A numerical model for the prediction of the flow, temperature field, particle trajectories, calcination process, and pulverized coal combustion is presented. For the purpose of 
numerical simulations, numerical model of calcination process and pulverized coal combustion was implemented into the commercial computational fluid dynamics code FIRE. Presented model is used to numerically study cement calciner's operating conditions and pollutant emissions. The study shows that it is possible to numerically simulate different thermo-chemical processes inside a cement calciner. By combining the information provided by the temperature field, the particle trajectories, and the decomposition and burnout rates, an interesting picture of the interdependence of their behavior is observed. The highly swirled flow enhances the mixing phenomena of pulverized limestone and coal particles, and prolongs the particle residence time. The highly decomposed limestone that comes out of the calciner suggests that this prolonged residence time is beneficial. Furthermore, the paper analyzes the influence of different parameters on the decomposition rate of limestone particles, burnout rate of coal particles, and pollutant emissions of a newly designed cement calciner. It can be concluded that most of the pollutants that are emitted from the calciner are related to the amount of fuel used. The results obtained by these simulations can be used for the optimization of cement calciner's fuel consumption, and thus its pollutant emissions. The paper demonstrates some important characteristics of cement calciner's operating conditions, which cannot be practically measured. The paper also show that CFD is a useful tool for plant design and process improvements, and that by using CFD engineers could gain an insight into process details. Together with experiments, CFD will be the basis for future cement calciners improvements.

Acknowledgments The authors wish to thank Dr. H. Maier from Gridlab GmbH for useful discussions and for providing the calciner's geometry for a CFD calculation. Authors also wish to thank A TEC AG for the input data needed for the calculation.

\section{References}

Baburić M, Raulot A, Duić N (2004) Implementation of discrete transfer radiation method into SWIFT computational fluid dynamics code. Therm Sci 8:293-301

Baum MM, Street PJ (1971) Predicting the combustion behavior of coal particles. Combust Sci Techn 3:231-243

De Soete GG (1975) Overall reaction rates of NO and $\mathrm{N}_{2}$ formation from fuel nitrogen, Proceeding 15th Int Symposium on Combust, The Combustion Institute, 1093-1102

Fidaros DK, Baxevanou CA, Dritselis CD, Vlachos NS (2007) Numerical modelling of flow and transport processes in a calciner for cement production. Powder Technol 171:81-95

FIRE_v2011_Manuals (2011), Graz, Austria
Fodor Z, Klemeš JJ (2011) Municipal solid waste as alternative fuelminimising emissions and effluents. Chem Eng Trans 25:31-38

Fodor Z, Klemeš JJ (2012) Waste as alternative fuel-minimising emissions and effluents by advanced design. Process Saf Environ Prot 90:263-284

Giddings D, Eastwick CN, Pickering SJ, Simmons K (2000) Computational fluid dynamics applied to a cement precalciner. Proc Inst Mech Eng Part A: J Power Energy 214:269-280

Görner K (1991) Technical combustion systems: fundamentals, modelling, simulation. Springer/Heidelberg, Berlin/Germany

Hu Z, Lu J, Huang L, Wang S (2006) Numerical simulation study on gas-solid two-phase flow in pre-calciner. Commun Nonlinear Sci Numer Simul 11:440-451

Huang L, Lu J, Wang S, Hu Z (2005) Numerical simulation of pollutant formation in precalciner. Can J Chem Eng 83:675-684

Huang L, Lu J, Xia F, Li W, Ren H (2006) 3-D mathematical modeling of an in-line swirl-spray precalciner. Chem Eng Process 45:204-213

Huanpeng L, Wentie L, Jianxiang Z, Ding J, Xiujian Z, Huilin L (2004) Numerical study of gas-solid flow in a precalciner using kinetic theory of granular flow. Chem Eng J 102:151-160

Jones WP, Lindstedt RP (1988) Global reaction scheme for hydrocarbon combustion. Combust Flame 73:233-249

Maroušek J (2012) Study on agriculture decision-makers behavior on sustainable energy utilization. J Agric Environ Ethics. doi:10. 1007/s10806-012-9423-x

Mikulčić H, Vujanović M, Fidaros DK, Priesching P, Minić I, Tatschl R, Duić N, Stefanović G (2012a) The application of CFD modelling to support the reduction of $\mathrm{CO}_{2}$ emissions in cement industry. Energy 45:464-473

Mikulčić H, von Berg E, Vujanović M, Priesching P, Perković L, Tatschl R, Duić N (2012b) Numerical modelling of calcination reaction mechanism for cement production. Chem Eng Sci 69: $607-615$

Mikulčić H, Vujanović M, Duić N (2013) Reducing the $\mathrm{CO}_{2}$ emissions in Croatian cement industry. Appl Energy 101:41-48

Mislej V, Novosel B, Vuk T, Grilc V, Mlakar E (2012) Combustion behaviour and products of dried sewage sludge-prediction by thermogravimetric analysis and monitoring the co-incineration process in a cement factory. Chem Eng Trans 29:685-690

Molina A, Murphy JJ, Winter F, Haynes BS, Blevins LG, Shaddix CR (2009) Pathways for conversion of char nitrogen to nitric oxide during pulverized coal combustion. Combust Flame 156:574-587

Sazhin SS, Sazhina EM, Faltsi-Saravelou O, Wild P (1996) The P-1 model for thermal radiation transfer: advantages and limitations. Fuel 75:289-294

Schnell U (1991) Calculation of the NOx emissions from pulverized coal combustion. VDI, Düsseldorf

Vad Mathiesen B, Lund H, Karlsson K (2011) 100 \% Renewable energy systems, climate mitigation and economic growth. Appl Energy 88:488-501

Villar A, Arribas JJ, Parrondo J (2012) Waste-to-energy technologies in continuous process industries. Clean Technol Environ Policy 14:29-39

Zhang Y, Cao SX, Shao S, Chen Y, Liu SL, Zhang SS (2011) Aspen Plus-based simulation of a cement calciner and optimization analysis of air pollutants emission. Clean Technol Environ Policy 13:459-468 